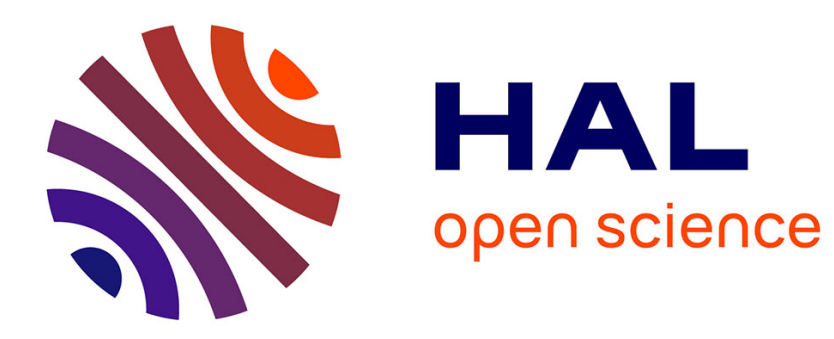

\title{
Social network, unemployment and sector trap
}

Manon Domingues dos Santos, Emmanuelle Taugourdeau

\section{To cite this version:}

Manon Domingues dos Santos, Emmanuelle Taugourdeau. Social network, unemployment and sector trap. Mathematical Social Sciences, 2021, 112, pp.61-71. 10.1016/j.mathsocsci.2021.03.014 . hal03420666

\section{HAL Id: hal-03420666 \\ https://hal.science/hal-03420666}

Submitted on 9 Nov 2021

HAL is a multi-disciplinary open access archive for the deposit and dissemination of scientific research documents, whether they are published or not. The documents may come from teaching and research institutions in France or abroad, or from public or private research centers.
L'archive ouverte pluridisciplinaire HAL, est destinée au dépôt et à la diffusion de documents scientifiques de niveau recherche, publiés ou non, émanant des établissements d'enseignement et de recherche français ou étrangers, des laboratoires publics ou privés. 


\title{
Social Network, Unemployment and Sector Trap
}

A theorical model explaining the case study of Portuguese immigrants on the French labour market

\section{Manon DOMINGUES DOS SANTOS* \& Emmanuelle TAUGOURDEAU†}

September 17, 2020

\begin{abstract}
This paper shows that social networks are likely to induce sector concentration and sector trap on the labor market. We develop a two-sector economy with endogenous allocation of labor force across sectors and social networks which favor transmission of job information. We show that social networks may induce sector concentration even when sectoral productivities and entry costs are perfectly symmetric. Moreover, we bring to the fore that social networks may also trap workers in low productive sectors. These results are in accordance with the migratory history and the situation of Portuguese immigrants on the French labor market.

Keywords: social networks, job search, labor markets, immigration.

JEL codes: E24, J31, J61, J64.
\end{abstract}

\section{Introduction}

In France, Portuguese immigrant workers are a singular community. Less unemployed and more concentrated in the industries of construction than natives and immigrants of other communities, children of Portuguese immigrants are more likely to work in the industries of construction than the children of natives and of immigrants of other communities as well. Why are Portuguese workers and their children so singular? Is there potential causal links between these singularities ? In which way are these links efficient, or not? This contribution provide an original and simple matching model which demonstrates that the density of the Portuguese social network is likely to explain all these stylised facts. The

\footnotetext{
*Université Gustave Eiffel, ERUDITE, email : msantos@u-pem.fr

${ }^{\dagger}$ CNRS, CREST, ENS Paris-Saclay, 5 avenue Henry Le Chatelier 91120 Palaiseau email : emmanuelle.taugourdeau@ensae.fr

${ }^{\ddagger}$ This paper is dedicated to our friend and colleague Carine Nourry who initiated this reflexion.
} 
density of the Portuguese social network improves information diffusion on job offers, which favours employment. Nevertheless, the density of the Portuguese social network induces the concentration of Portuguese immigrants as well as of theirs descendants in relatively low productive industries, where they were initially located.

Actually, $5 \%^{1}$ of Portuguese men are unemployed in France, whereas this proportion reaches respectively $9 \%$ and $18 \%$ among natives and other immigrants. Nevertheless, differentials in levels of qualification, which usually explains a main part of unemployment rate differentials, cannot explain these singularities. Indeed, more than $60 \%$ of the Portuguese men have no qualification, whereas this rate is equal to $35 \%$ for other immigrants and only to $17 \%$ for natives. Among unskilled male workers, unemployment differential gap reaches 12 points of percentage between Portuguese and native workers and 18 points of percentage between Portuguese and other immigrant workers. Obviously, Portuguese workers are likely to distinguish with respect to other observed or unobserved characteristics, which favour the productivity and the employability. First, the work by Bauer et al. (2002) could carry weight in this sense. Using a dataset provided by the German Labor Office, they advocate that Portuguese immigrants are positively self-selected in terms of unobserved skills when compared to the German population. Second, one could argue that their high propensity to return to their home country could incite them to work harder. Indeed, nearly $24 \%$ of immigrants in France declare they intend to return to their home country whereas this rate reaches more than $30 \%$ among the Portuguese workers (Domingues dos Santos and Wolff (2010)). Hence, according to Dustmann (2000), as the leisure time is relatively more expansive for a temporary immigrant than for a permanent one, the temporary nature of the Portuguese immigration is likely to reduce the reservation wages of these workers and to induce them to work harder while being abroad. Nevertheless, these arguments do not explain why 57\% of unskilled Portuguese males are working in the industries of construction whereas this rate is equal to $13 \%$ among natives and $24 \%$ among other immigrants. These arguments neither explain why their children tend to follow their steps. Indeed, Portuguese immigrants are not significantly more likely to have worked in the industries of construction before their migration than other immigrants (Domingues Dos Santos, 2005), which exclude a migration selection bias regarding sectoral specific human capital. Moreover, children of Portuguese are more likely to choose short and vocational studies and to train in construction trades than other children from comparable socio-economic backgrounds (Brinbaum and Kieffer, 2009; Lainé and Okba,

\footnotetext{
${ }^{1}$ French Labour Force Survey, 2018.
} 
2005).

The aim of this paper is to provide an original and simple matching model which highlights that employment and industries concentration of the Portuguese community can also be explained by the (in)efficiency of their social network. We argue that the Portuguese community in France constitutes a particular dense social network, which substantially furthers the employment research of its members, especially in the construction sector where the community was originally employed. This idea is notably set on the following observation: over $55 \%$ of the Portuguese employees found their job through friends and relatives, whereas this rate reaches less than $39 \%$ for other immigrants and only $32 \%$ for natives. Then it seems that Portuguese workers are more likely to gather information about job opportunities through their network of personal contacts than through more formal methods as employment agencies or direct applications. This social network efficiency can lead them and their descendants to a trade-off between job opportunity and job productivity inducing in fine an endogenous concentration of the community in relatively low productive activities.

The central role of social networks in the labor market and in the migration pattern is well documented, even if these two trends of the literature are quite not connected. First, concerning the role of social networks in the labor market, the major part of the related literature lays emphasis on the importance of friends and relatives as sources of employment information. More precisely, some contributions analyse the endogenous formation of such informational networks: Following the seminal works by Granovetter (1974) and Boorman (1975), they intend to explain the size and the structure of such networks (Jackson and Wolinsky, 1996; Calvó-Armengol and Jackson, 2002; Calvó-Armengol, 2004). Other studies focus on the choice between alternative job search methods, such as direct application, advertisements, job centers or friends and relatives route, and test their efficiency on the outflow of unemployment. Most of these empiric studies conclude in the effectiveness of friends and relatives route (Holzer, 1988; Blau and Robins, 1990; Addison and Portugal, 2002). Finally, theoretical papers analyze the efficiency of job-worker matching process when information about job vacancies can be gathered through social contacts in order to determine an optimal resort to social networks (Calvó-Armengol and Zenou, 2005). Following these contributions, the existence of social networks is generally supposed to increase outflow unemployment rates and wages. Nevertheless, these theoretical papers do not propose empirical relevance of their results and tell nothing about the distribution of the labor force between industries in such a context. Second, concerning migration 
networks, the main part of the related literature addresses the question of migrants clustering. Prominent examples of the clustering of migrants are concentrations of Turks in Germany, Italians in Argentine or Greeks in Australia. The prevailing explanation for ethnic concentration is the existence of beneficial network externalities. The setting of previous migrants encourages the arrival of new ones in three ways: they provide information about the regional labor and rent markets, they are likely to help them in their settlement process and they increase the amount of ethnic goods available. This literature focuses on two issues: bring to the fore the spatial concentration process of immigrants (Bartel, 1989; Carrington et al., 1996) and shed some light on some consequences of this spatial clustering (Chiswick and Miller, 1995; Chiswick et al., 2002). Nevertheless, the connection between immigrants' informational network, job search activity, industrial concentration and migratory history have not been explicitly formalized.

Based on the seminal model of Pissarides (2000), This paper demonstrates that the transmission of job information within a community improves the matching efficiency which contributes to lower unemployment and increase wages (Section 2). When workers choose their allocations between sectors, this information asset is likely to induce sector concentration even when sectors and sector entry costs are perfectly symmetric. In this case, we derive the condition allowing for a lower average unemployment and a higher average welfare in the equilibria with sector concentration (Section 3). Whereas asymmetry with respect to sector productivity favours concentration in the most productive sector, asymmetry with respect to entry costs favours concentration in the sector where fixed entry costs are the lowest. Nevertheless, we show that social network is likely to trap workers in a low productive sector. Hence, by historical chance, a community may be initially concentrated in a sector where the level of productivity is the same than in other sectors. This concentration increases relative matching efficiency and decreases relative entry cost in this sector. Then, even if a technological shock decreases relative productivity in the sector where the community is a priori concentrated, the community may stay concentrated in this relatively low productive sector (Section 4). The migratory history and the relative situation on the labor market of the Portuguese community in France can then be partially interpreted in the light of the results of the model developed in this paper (Conclusion). 


\section{The Model}

The basic environment borrows from Pissarides (2000) matching model. We consider an economy with $N$ workers allocated among two sectors ${ }^{2}$ indexed by $i=1,2$. Time is continuous. Workers are risk neutral, infinitely lived and discount the future at rate $r>0$. Each worker supplies one unit of labor and can be either employed, producing and earning a wage per unit of time denoted by $w_{i}$, or unemployed, searching for a job and getting an income denoted by $z$. We denote by $N_{i}, U_{i}$, and $L_{i}$ respectively the number of workers, unemployed workers and employees in sector $i$, with : $N_{i}=U_{i}+L_{i}, i=1,2$ and $N_{1}+N_{2}=1$.

In each sector, an endogenously sized continuum of competitive firms produce a numeraire good thanks to labor. Each firm has one job that can be either filled and produces $y_{i}$ units of output or vacant and searching. The cost of a vacant job per unit of time is denoted by $h$ whereas each filled job has an exogenous probability of being destroyed per unit of time, denoted by $q$.

\section{$2.1 \quad$ Matching}

According to the standard matching model, vacant jobs and unemployed workers are matched through an imperfect process. In order to introduce job offers transmission between workers, the usual matching process is modified. It is assumed that, per unit of time, $C_{i}$ workers of sector $i$ hear speaking about a job vacancy in sector $i$ with $C_{i}=$ $C\left(N_{i}, V_{i}\right)$, where $V_{i}$ denotes the number of job vacancies. Function $C\left(N_{i}, V_{i}\right)$ is a contact function which defines the number of job offers in sector $i$ that have been actually received by a worker of sector $i$. For the sake of simplicity, we suppose that only workers of sector $i$ are likely to get information about job vacancies in this sector and that all workers of sector $i$ face the same probability to hear speaking about a vacant job ${ }^{3}$. Then, information about job vacancies is randomly disseminated among workers of the sector. Nevertheless, whereas an unemployed worker who received a job offer fills it, an employee transmits an offer that he receives to an unemployed worker of his sector with probability $p_{i}$. Here, $p_{i}$ is a parameter which figures the density of the social network.

The contact function satisfies the standard properties: $C\left(N_{i}, V_{i}\right)$ is increasing, continuously

\footnotetext{
${ }^{2}$ We refer to sectors but we could also refer to regions.

${ }^{3}$ Qualitative results would not be modified if we suppose that workers in sector $j$ can receive direct and indirect information about job offers in sector $i$, as long as their probability of receiving such information is lower than for workers located in sector $i$.
} 
differentiable, homogenous of degree one, and yields no contact if the mass of workers or the mass of vacant jobs is nil. The linear homogeneity of the function allows us to write the transition rate for vacancies in sector $i$, denoted by $\eta_{i}$, as

$$
\eta_{i}=c\left(\theta_{i}\right)\left[u_{i}+p_{i}\left(1-u_{i}\right)\right]
$$

where $\theta_{i}=\frac{V_{i}}{N_{i}}$ and $c\left(\theta_{i}\right)=C\left(1 / \theta_{i}, 1\right)$.

Similarly, the job finding rate in sector $i$, denoted by $s_{i}$ is given by

$$
s_{i}=\theta_{i} c\left(\theta_{i}\right)\left[\frac{u_{i}+p_{i}\left(1-u_{i}\right)}{u_{i}}\right]
$$

\subsection{Bargaining}

The value functions of an unemployed worker and an employee in sector $i$, denoted by $V_{u, i}$ and $V_{e, i}$ respectively, satisfy the following equations :

$$
r V_{u, i}=z+s_{i}\left(V_{e, i}-V_{u, i}\right)
$$

and

$$
r V_{e, i}=w_{i}+q\left(V_{u, i}-V_{e, i}\right)
$$

An unemployed worker in sector $i$ receives unemployment benefits z. He finds a job with probability $s_{i}$ which yields a capital gain of $\left(V_{e, i}-V_{u, i}\right)$. An employed worker receives a wage $w_{i}$ and looses his job with probability $q$ which leads to a capital loss of $\left(V_{u, i}-V_{e, i}\right)$.

The asset values of a vacant job and a filled job, denoted by $\Pi_{v, i}$ and $\Pi_{e, i}$ respectively, satisfy the following equations :

$$
r \Pi_{v, i}=-h+\eta_{i}\left(\Pi_{e, i}-\Pi_{v, i}\right)
$$

and

$$
r \Pi_{e, i}=y-w_{i}+q\left(\Pi_{v, i}-\Pi_{e, i}\right)
$$

The value of a vacancy is determined by the (per unit of time) cost of posting a vacancy and the gain from filling the job. The value of a job is determined by the instantaneous profit i.e. the difference between the productivity and the wage, and the loss in value should a break-up occur.

Firms are assumed to post vacancies in each sector up to the point where the expected income from posting a further vacancy is nil. Then, the free entry condition reads as :

$$
\Pi_{v, i}=0
$$


Wages are assumed to be the outcome of a bilateral Nash bargaining between each firm and worker:

$$
\underset{w_{i}}{\operatorname{Max}}\left(V_{e, i}-V_{u, i}\right)^{\beta}\left(\Pi_{e, i}-\Pi_{v, i}\right)^{1-\beta}
$$

The surplus of each match, defined by $S_{i}=V_{e, i}-V_{u, i}+\left(\Pi_{e, i}-\Pi_{v, i}\right)$, is shared according to the Nash solution that reads:

$$
V_{e, i}-V_{u, i}=\beta S_{i} \quad \text { and } \quad \Pi_{e, i}-\Pi_{v, i}=(1-\beta) S_{i}
$$

where $\beta \in[0,1]$ denotes the share that accrues to the worker.

Equations (3), (4), (5), (6), (7) and (8) imply that the outflow unemployment rate and the transition rate for vacancies in sector $i$ satisfy :

$$
\frac{h}{\eta_{i}}=\frac{(1-\beta)(y-z)}{r+q+\beta s_{i}}
$$

Finally, the equilibrium of flows in sector $i$ reads:

$$
q\left(1-u_{i}\right)=\theta_{i} c\left(\theta_{i}\right)\left[u_{i}+p_{i}\left(1-u_{i}\right)\right]
$$

\subsection{Sectoral equilibrium}

In this section, we characterize the sectoral equilibrium for a given allocation of the labour force between sectors (See Appendix 1 for analytical details).

Equations (9) and (10) imply that the equilibrium unemployment rate in sector $i$, denoted by $u_{i}^{*}$, and the equilibrium value of the labor market "tightness", denoted by $\theta_{i}^{*}$, verify:

$$
\left\{\begin{array}{l}
\phi\left(\theta_{i}^{*}, u_{i}^{*}\right)=0 \\
\psi\left(\theta_{i}^{*}, u_{i}^{*}\right)=0
\end{array}\right.
$$

with

$$
\begin{aligned}
\phi\left(\theta_{i}, u_{i}\right) & =q\left(1-u_{i}\right)-\theta_{i} c\left(\theta_{i}\right)\left(u_{i}+p_{i}\left(1-u_{i}\right)\right) \\
& \text { and } \\
\psi\left(\theta_{i}, u_{i}\right) & =\frac{h}{c\left(\theta_{i}\right)\left(u_{i}+p_{i}\left(1-u_{i}\right)\right)}-\frac{(1-\beta)(y-z)}{r+q+\beta q \frac{\left(1-u_{i}\right)}{u_{i}}}
\end{aligned}
$$

The system of equations (11) defines a unique equilibrium $\left(u_{i}^{*}, \theta_{i}^{*}\right)$ since the first function, $\phi(.,$.$) , is decreasing in u_{i}$ and decreasing in $\theta_{i}$, while the second one, $\psi(.,$.$) , is$ decreasing in $u_{i}$ and increasing in $\theta_{i}$. 
In order to investigate the properties of the sectoral labor market equilibrium, we determine the impact of the tightness of the social contacts, $p_{i}$, on unemployment, wages and workers' satisfaction. By removing equations (11), one can explicit $\theta_{i}^{*}$ with respect to $u_{i}^{*}$ and $p_{i}$. We can deduce an implicit relation between $u_{i}^{*}$ and $p_{i}$ such that

$$
\xi\left(u_{i}^{*}, p_{i}\right)=0 \quad \text { where } \quad \frac{\partial u_{i}^{*}}{\partial p_{i}}=-\frac{\xi_{p_{i}}\left(u_{i}^{*}, p_{i}\right)}{\xi_{u_{i}^{*}}\left(u_{i}^{*}, p_{i}\right)}<0
$$

And, according to equations $(3),(4),(5),(6),(7)$ and (8), the equilibrium wage verifies :

$$
w_{i}^{*}=w_{i}^{*}\left(u_{i}^{*}\right) \quad \text { where } \quad \frac{\partial w_{i}^{*}}{\partial u_{i}^{*}}<0
$$

(See Appendix 1 for more details about the sign of (12) and (13)).

Finally, equations (12) and (13) induce:

$$
\frac{\partial w_{i}^{*}}{\partial p_{i}}=\frac{\partial w_{i}^{*}}{\partial u_{i}^{*}} \frac{\partial u_{i}^{*}}{\partial p_{i}}>0
$$

On the one hand, for a given number of vacant jobs, an increase in the rate of job offer transmission from employees to unemployed workers increases the probability of getting a job offer for an unemployed worker and so his probability of finding a job. This contributes to increase the outflow unemployment rate ( $s_{i}$ increases) and therefore to lower unemployment. On the other hand, this improvement of the outside opportunities of employees pushes the bargained wages up, which contributes to decrease the number of vacant jobs and increase unemployment. Nevertheless, regarding to the number of filled job offers, the increase in labor cost never offsets the initial improvement of the matching process.

Concerning the expected utility of an unemployed worker in sector $i$, equations (3), (4), (5), (6), (7), (8, (12) and (15) intuitively imply that :

$$
V_{u, i}^{*}=V_{u, i}^{*}\left(u_{i}^{*} ; p_{i}\right) \quad \text { with } \quad \frac{\partial V_{u, i}^{*}}{\partial u_{i}^{*}}<0 \quad \text { and } \quad \frac{\partial V_{u, i}^{*}}{\partial p_{i}}>0
$$

\section{$3 \quad$ Labor force allocation among sectors}

The aim of this section is to determine the equilibrium allocation of workers between sectors. We consider that the labor force we study is a specific community (call it Portuguese workers). We assume that each worker chooses once and for all his sector of activity. When entering a sector, a worker $j$ supports an entry cost denoted by $e_{i j}$ with $i=1,2$. 
Entry costs in each sector have two components. The first component is common to each worker of the sector. We denote this component by $\bar{e}_{i}$ and set the differential between sectors as $\bar{e}=\bar{e}_{1}-\bar{e}_{2}$. The second component is specific to each worker and is denoted by $\tilde{e}_{i j}$. It reflects the heterogeneity in the capacity to acquire general or specific skills ${ }^{4}$. The distribution of the differentials of entry costs between sector 1 and 2 specific to each worker, $\tilde{e}_{j}=\tilde{e}_{1 j}-\tilde{e}_{2 j}$, is represented by a distribution function over the interval $]-\infty,+\infty[$, denoted by $F(e)$, with $F($.$) being symmetric in relation to zero and F(0)=\frac{1}{2}$. Finally, the entry cost for each individual is $e_{i j}=\bar{e}_{i}+\tilde{e}_{i j}$ and the differential of entry costs writes $e_{j}=\bar{e}+\tilde{e}_{j}$.

We first consider that sectors are perfectly symmetric, so that they face identical productivity $\left(y_{1}=y_{2}=y\right)$ and have symmetric fixed sector entry costs $(\bar{e}=0)$. These assumptions will be levied in Section 4.

\subsection{Exogenous employee probability of transmission}

In this section we assume that the probability that an employee transmits a job is fixed and equal across sectors $\left(p_{1}=p_{2}=\bar{p}\right)$. Therefore, we consider that sectors are perfectly symmetric.

Let's denote by $\Delta V$ the expected utility differential between unemployed workers in sector 1 and 2. A worker chooses to work in sector 1 as long as $V_{u_{1}}-e_{1 j}>V_{u_{2}}-e_{2 j}$ which rewrites $\Delta V \geq e_{j}$, otherwise he decides to work in sector 2. According to (15), one gets :

$$
\Delta V^{*}=\Delta V\left(u_{1}^{*}, u_{2}^{*}\right) \quad \text { with } \quad \frac{\partial \Delta V}{\partial u_{1}^{*}}<0 \quad \text { and } \quad \frac{\partial \Delta V}{\partial u_{2}^{*}}>0
$$

Given that sectors are perfectly symmetric, the marginal individual who is indifferent between both sectors is the one with $e_{j}=e=0$. Therefore, the size of the labor force participating in each sector is given by:

$$
N_{i}^{*}=\chi_{i} \int_{-\infty}^{0} f(e) d e+\left(1-\chi_{i}\right) \int_{0}^{\infty} f(e) d e
$$

where $f(e)$ is the density of the distribution function $F$ with $\chi=1$ for $i=1$ and $\chi=0$ for $i=2$. Since $F(0)=\frac{1}{2}$, it results that the only equilibrium reduces to an equal share of the population across sectors with $N_{1}^{*}=N_{2}^{*}=\frac{1}{2}$.

\footnotetext{
${ }^{4}$ Qualitative results of the model would not be modified by assuming that this component is proportional to the level of the sectoral productivity
} 


\subsection{Endogenous employee probability of transmission}

In this section, we suppose that the probability that an employee transmits a job offer to an unemployed worker is an increasing function of both the number of links and the closeness of social links. Then, we suppose that the probability of job offer transmission is an increasing function of the sector labor force size. This assumption implies that:

$$
p_{i}=p_{i}\left(\lambda, N_{i}\right) \quad \text { with } \quad \frac{\partial p_{i}}{\partial \lambda} \geq 0, \quad \frac{\partial p_{i}}{\partial N_{i}} \geq 0
$$

where $\lambda$ represents the closeness of social links and $N_{i}$ approximates the number of direct personal links. Furthermore, we assume that $\frac{\partial^{2} p_{i}}{\partial N_{i}^{2}} \leq 0$.

To define the potential allocation of workers between sectors, we determine the differential of entry costs for the "marginal" worker who is indifferent between working in sector 1 or in sector 2 . We denote this differential $e^{*}$, such that $e^{*}=\Delta V\left(N_{1}\right)=V_{u_{1}}-V_{u_{2}}{ }^{5}$ :

$$
e^{*}=(y-z) \beta q \frac{r+q}{r}\left(\frac{u_{2}-u_{1}}{\left((r+q) u_{1}+q \beta\left(1-u_{1}\right)\right)\left((r+q) u_{2}+\beta q\left(1-u_{2}\right)\right)}\right)
$$

Workers who have a differential of entry costs lower than $e^{*}$ choose to work in sector 1 , whereas the others choose to work in sector 2. According to equations (12), (16) and (17), the equilibrium unemployment rates and workers allocations $\left(u_{1}^{*}, u_{2}^{*}, N_{2}^{*}, N_{2}^{*}\right)$, verify

$$
\left\{\begin{array}{c}
\xi\left(u_{1}, p\left(\lambda, N_{1}\right)\right)=0 \\
\xi\left(u_{2}, p\left(\lambda, 1-N_{1}\right)\right)=0 \\
N_{1}=\int_{-\infty}^{e^{*}} f(e) d e=F\left(e^{*}\right) \\
N_{2}=1-N_{1}
\end{array}\right.
$$

The existence and multiplicity of equilibria depend on the properties of the function $F\left[\Delta V\left(N_{1}\right)\right]$ and notably of the sign of its second derivative, which is a priori undetermined.

Nevertheless, we can bring to the fore several results:

\section{Proposition 1}

i) The symmetric equilibrium allocation, such that $\left(N_{1}^{*}, N_{2}^{*}\right)=\left(\frac{1}{2}, \frac{1}{2}\right)$, is always an equilibrium.

ii) A sufficient condition for the existence of multiple equilibria is :

$$
(y-z)>\frac{r}{(r+q) \beta q} \frac{\left((r+q) u_{s}^{*}+\beta q\left(1-u_{s}^{*}\right)\right)^{2}}{-2 u^{\prime} f(0)}
$$

\footnotetext{
${ }^{5}$ Here $e^{*}=\tilde{e}^{*}$ since $\bar{e}=0$.
} 
with $u^{\prime}=\frac{\partial u_{1}^{*}}{\partial N_{1}}=-\frac{\partial u_{2}^{*}}{\partial N_{2}}<0$ at the symmetric equilibrium and $u_{s}^{*}$ is the symmetric equilibrium unemployment rate.

iii) Due to the perfect symmetry of the model, when equilibrium $\left(N_{1}^{*}, N_{2}^{*}\right)=(x, y)$ with $x \neq y$ exists, an equilibrium with $\left(N_{1}^{*}, N_{2}^{*}\right)=(y, x)$ also exists.

Proof. See Appendix 2

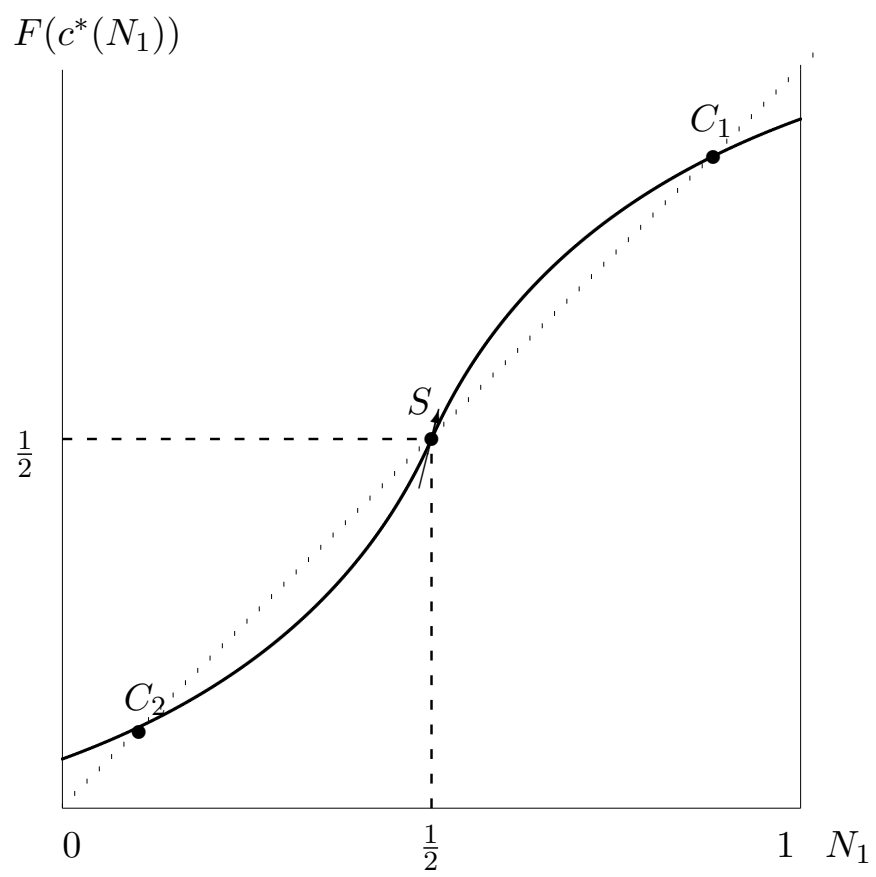

Figure 1: Multiple equilibria

Proposition 1 highlights that social networks are likely to induce equilibria with industrial concentration while sectors are perfectly symmetric as depicted in Figure 1. This is the case when the net productivity $(y-z)$ is sufficiently large. Workers with intermediate differential of entry costs are pushed to agglomerate in the same sector. Multiple equilibria are all the more existing when the cost function density is concentrated around the mean (i.e around 0 and $f(0)$ is high). This implies that the asymmetric equilibria split the population in the two sectors so that the concentrated sector benefits from a very high share of the population ( $N_{i}^{*}$ is close to 1 for $i=1$ or 2 ). However, we can observe that when workers have no bargaining power $(\beta=0)$, condition on the net productivity in ii) 
is never satisfied.

Analyzing and comparing symmetric and asymmetric equilibria when existing leads to the following proposition:

Proposition 2 When multiple equilibria exist,

i) unemployment rate is lower in the sector where labor force concentrates and wages are higher in that sector.

ii) $\frac{\partial^{2} u}{\partial p^{2}}>0$ is a sufficient condition ensuring that an asymmetric equilibrium generates a higher aggregated level of production and a lower average unemployment rate than the symmetric equilibrium.

iii) When $\frac{\partial^{2} u}{\partial p^{2}}>0, \frac{\partial^{2} u_{i}}{\partial N_{1}^{2}}>\frac{\left((1-\beta) r q\left(1+u^{2}\right)+(q+r u)^{2}\right)((q+r) u+\beta q(1-u))}{2(1-\beta) q(q+r)^{2}}\left(\frac{\partial u_{i}}{\partial N_{1}}\right)^{2}$ is a sufficient condition ensuring that asymmetric equilibria $C_{1}$ and $C_{2}$ are welfare improving compared to the symmetric equilibrium.

Proof. In order to compare equilibria, we consider the equilibrium $C_{1}$ defined by $\left(N_{1}^{*}, N_{2}^{*}\right)=(x, 1-x)$ with $x>\frac{1}{2}$ (the symmetric reasoning works for equilibrium $C_{2}$ with $\left.x<\frac{1}{2}\right)$.

i) In equilibrium $C_{1}$, workers concentrate in sector 1 which implies a lower level of unemployment in that sector through a better network effect since $\frac{\partial u_{i}}{\partial N_{i}}<0$. At equilibrium $C_{1}$, this implies $u_{1}^{*}<u_{2}^{*}$ and $w_{1}^{*}>w_{2}^{*}$ since $\frac{\partial w_{i}}{\partial p_{i}}>0$ and $\frac{\partial p_{i}}{\partial N_{i}}>0$.

ii) Aggregate production is defined by : $N_{1}\left(1-u_{1}\right) y+N_{2}\left(1-u_{2}\right) y$ which at the symmetric equilibrium reduces to $\left(1-u_{s}^{*}\right) y$. Comparing equilibrium $C_{1}$ to the asymmetric equilibrium, we obtain:

$$
N_{1}^{*}\left(1-u_{1}^{*}\right) y+N_{2}^{*}\left(1-u_{2}^{*}\right) y>\left(1-u_{s}^{*}\right) y \Longleftrightarrow N_{1}^{*}>\frac{u_{2}^{*}-u_{s}^{*}}{u_{2}^{*}-u_{1}^{*}}
$$

since $u_{2}^{*}>u_{s}^{*}>u_{1}^{*}$.

Condition $\frac{u_{2}^{*}-u_{s}^{*}}{u_{2}^{*}-u_{1}^{*}}<\frac{1}{2}$ is a sufficient condition to get the result since $N_{1}>\frac{1}{2}$ at equilibrium $C_{1}$.

$$
\frac{u_{2}^{*}-u_{s}^{*}}{u_{2}^{*}-u_{1}^{*}}<\frac{1}{2} \Longleftrightarrow u_{2}^{*}-u_{s}^{*}>u_{s}^{*}-u_{1}^{*}
$$

which is verified if $\frac{\partial^{2} u_{i}}{\partial\left(N_{i}^{*}\right)^{2}}>0$.

Since $\frac{\partial^{2} u_{i}}{\partial\left(N_{i}^{*}\right)^{2}}=\frac{\partial^{2} u_{i}}{\partial\left(p_{i}^{*}\right)^{2}}\left(\frac{\partial p_{i}}{\partial\left(N_{i}\right)}\right)^{2}+\frac{\partial u_{i}}{\partial p_{i}} \frac{\partial^{2} p_{i}}{\partial\left(N_{i}^{*}\right)^{2}}>0$, with $\frac{\partial u_{i}}{\partial p_{i}}<0$ and $\frac{\partial^{2} p_{i}}{\partial\left(N_{i}^{*}\right)^{2}}<0$, we can state that a sufficient condition ensuring $\frac{\partial^{2} u_{i}}{\partial\left(N_{i}^{*}\right)^{2}}>0$ is $\frac{\partial^{2} u_{i}}{\partial\left(p_{i}^{*}\right)^{2}} \geq 0$. 
The same condition applies for the average unemployment rate since

$$
N_{1}^{*}\left(1-u_{1}^{*}\right) y+N_{2}^{*}\left(1-u_{2}^{*}\right) y>\left(1-u_{s}^{*}\right) y \Longleftrightarrow N_{1}^{*} u_{1}^{*} y+N_{2}^{*} u_{2}^{*} y<u_{s}^{*} y
$$

iii) The social welfare defined by $S W=N_{1}\left(u_{1} V_{u_{1}}+\left(1-u_{1}\right) V_{e_{1}}\right)+\left(1-N_{1}\right)\left(u_{2} V_{u_{2}}+(1-\right.$ $\left.\left.u_{2}\right) V_{e_{2}}\right)$ can be rewritten as $S W_{a}=N_{1} W_{1}+\left(1-N_{1}\right) W_{2}$ for an asymmetric equilibrium with $W_{i}=u_{i} V_{u_{i}}+\left(1-u_{i}\right) V_{e_{i}}$ is the average utility in sector $i$ and $S W_{s}=W$ for a symmetric equilibrium.

Similarly to the previous analysis we can show that

$$
S W_{a}>S W_{s} \Longleftrightarrow N_{1}^{*}>\frac{W-W_{2}}{W_{1}-W_{2}}
$$

with $W_{1}-W_{2}>W-W_{2}>0$. Since $N_{1}>\frac{1}{2}$, a sufficient condition that ensures $S W_{a}>S W_{s}$ is $\frac{W-W_{2}}{W_{1}-W_{2}} \leq \frac{1}{2}$, and we have

$$
\frac{W-W_{2}}{W_{1}-W_{2}} \leq \frac{1}{2} \Longleftrightarrow W_{2}-W \leq W_{1}-W
$$

Then, we need to show that condition $\frac{\partial^{2} W}{\partial N_{1}^{2}}>0$ is verified. We can rewrite:

$$
\frac{\partial W}{\partial N_{1}}=\frac{\partial W_{i}}{\partial u_{i}} \frac{\partial u_{i}}{\partial N_{1}}
$$

and then

$$
\frac{\partial^{2} W}{\partial N_{1}^{2}}=\frac{\partial^{2} W_{i}}{\partial u_{i}^{2}}\left(\frac{\partial u_{i}}{\partial N_{1}}\right)^{2}+\frac{\partial W_{i}}{\partial u_{i}} \frac{\partial^{2} u_{i}}{\partial N_{1}^{2}}
$$

According to the previous item of the proposition, we know that $\frac{\partial^{2} u_{i}}{\partial N_{1}^{2}}>0$ when $\frac{\partial^{2} u_{i}}{\partial p^{2}}>0$. The effect of the unemployment rate on the average utility $W_{i}=\left(u_{i} V_{u_{i}}+\left(1-u_{i}\right) V_{e_{i}}\right)$ in each sector $i$ is given by (See Appendix 3 for details):

$$
\frac{\partial W_{i}}{\partial u_{i}}=\frac{\partial\left(u_{i} V_{u_{i}}+\left(1-u_{i}\right) V_{e_{i}}\right)}{\partial u_{i}}<0
$$

Then, we can deduce that the average utility at equilibrium $C_{1}$ is higher in the sector with high concentration while this is the contrary in the sector with low concentration. Furthermore (See Appendix 3 for details),

$$
\frac{\partial^{2} W_{i}}{\partial u_{i}^{2}}=\frac{\partial^{2}\left(u_{i} V_{u_{i}}+\left(1-u_{i}\right) V_{e_{i}}\right)}{\partial u_{i}^{2}}>0
$$

implies that compared to the unemployment rate at the symmetric equilibrium, a change in the employment rate of $1 \%$ leads to a benefit of the average welfare in the concentrated 
sector that is higher than the loss of welfare in the other sector.

Then

$$
\begin{aligned}
\frac{\partial^{2} W}{\partial N_{1}^{2}}>0 \Longleftrightarrow \frac{\partial^{2} u_{i}}{\partial N_{1}^{2}} & >-\frac{\frac{\partial^{2} W_{i}}{\partial u_{i}^{2}}}{\frac{\partial W_{i}}{\partial u_{i}}}\left(\frac{\partial u_{i}}{\partial N_{1}}\right)^{2} \\
& >\frac{\left((1-\beta) r q\left(1+u_{i}^{2}\right)+\left(q+r u_{i}\right)^{2}\right)\left((q+r) u_{i}+\beta q\left(1-u_{i}\right)\right.}{2(1-\beta) q(q+r)^{2}}\left(\frac{\partial u_{i}}{\partial N_{1}}\right)^{2}
\end{aligned}
$$

The density of the social network decreases the industrial unemployment rates, increases wages and favours industrial concentration. Since the benefit of the average welfare in the concentrated sector is higher than the loss of welfare in the other sector, the concentration of the labor force in one sector that arises because of the network effect implies that the social welfare in the concentrated sector outweights the social loss in the deconcentrated sector.

\subsubsection{Simulation}

Our computational exercise illustrates Proposition 1 and 2's results and allows us to compare the different equilibria outcomes.

To this end, a contact function of the Cobb-Douglas form is assumed, such that $\left.c\left(\theta_{i}\right)=\theta_{i}^{\mu}, \mu \in\right]-1,0[$. The distribution of the differentials of entry costs, $F(e)$, is represented by a Normal distribution $N(0, \sigma)$. Moreover, we suppose that the relation between the probability of job offer transmission, the network tightness and the network size is represented by the following function $p_{i}\left(\lambda, N_{i}\right)=\lambda N_{i}^{\alpha}$. Finally, the parameters values are closed to the ones which are usually used to represent an European labor market. They are reported in Table 1.

\begin{tabular}{|c|c|c|c|c|c|c|c|c|c|}
\hline$y$ & $\alpha$ & $z$ & $r$ & $q$ & $h$ & $\beta$ & $\mu$ & $\lambda$ & $\sigma$ \\
\hline 1 & 1 & 0.5 & 0.05 & 0.1 & 0.1 & 0.5 & -0.5 & 0.2 & 1 \\
\hline
\end{tabular}

Table 1: Parameter Values

Figure 2 graphs both equations $\xi\left(u_{1}^{*}, p\left(\lambda, F\left(\Delta V\left(u_{1}^{*}, u_{2}^{*}\right)\right)\right)\right)=0$ and $\xi\left(u_{2}^{*}, p\left(\lambda, 1-F\left(\Delta V\left(u_{1}^{*}, u_{2}^{*}\right)\right)\right)\right)=$ 0 when $\alpha=1$. Table 2 summarizes the computational results for alternative values of $\alpha$ and $y$.

Table 2 shows that multiple equilibria exist for specific values of the parameters as shown in Proposition 1 ii). When the productivity level is low $(y=0.75)$ and then the dif- 


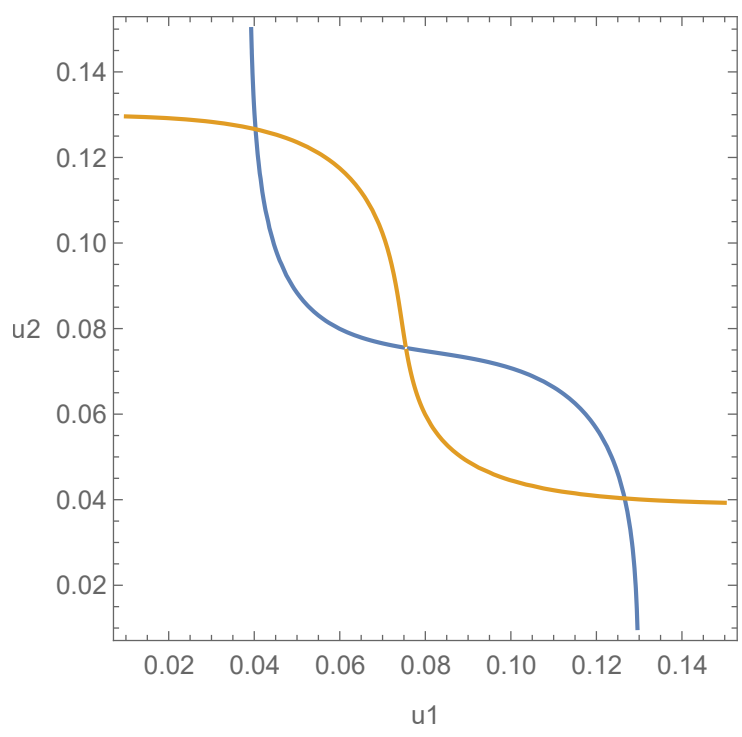

Figure 2: For $\alpha=1$ and $y=1$

\begin{tabular}{|l|c|c|c|c|c|c|c|c|}
\cline { 2 - 10 } \multicolumn{1}{c|}{} & \multicolumn{4}{c|}{ Symmetric Equilibrium } & \multicolumn{4}{c|}{\begin{tabular}{c} 
Asymmetric Equilibria \\
\multicolumn{1}{c|}{}
\end{tabular}} \\
\hline & $u_{1}^{*}=u_{2}^{*}=u_{s}^{*}$ & $N_{1}^{*}$ & $W^{*}$ & $u_{i}^{*}$ & $u_{j}^{*}$ & $N_{i}^{*}$ & $u_{a}^{*}$ & $W^{*}$ \\
\hline Benchmark & 7.55 & 50 & 18.34 & 4.03 & 12.66 & 97 & 4.27 & 19.01 \\
\hline$\alpha=0.5$ & 5.58 & 50 & 18.69 & 4.44 & 8.31 & 82 & 5.09 & 18.84 \\
\hline$y=1.5$ & 4.98 & 50 & 27.71 & 2.16 & 10.26 & 100 & 2.16 & 28.96 \\
\hline$y=0.75$ & 10.98 & 50 & 13.85 & - & - & - & - & - \\
\hline
\end{tabular}

Table 2: Simulation Results (in \% except for $W^{*}$ )

ference $(y-z)$, the only equilibrium that remains is the symmetric one. More importantly, simulations enable us to rank the equilibria according to the average unemployment rate and the welfare. For each case where multiple equilibria exist, the unemployment rate of the economy $\left(u_{a}^{*}=N_{1}^{*} u_{1}^{*}+N_{2}^{*} u_{2}^{*}\right)$ is lower with an asymmetric equilibrium compared to the symmetric one $\left(u_{a}^{*}<u_{s}^{*}\right)$. It immediately induces that the total level of production of the economy defined as $N_{1}^{*}\left(1-u_{1}^{*}\right) y+N_{2}^{*}\left(1-u_{2}^{*}\right) y$ is higher with asymmetric equilibria. Finally, when we calculate the welfare of the economy defined as

$$
W^{*}=N_{1}\left(u_{1} V_{u_{1}}+\left(1-u_{1}\right) V_{e_{1}}\right)+\left(1-N_{1}\right)\left(u_{2} V_{u_{2}}+\left(1-u_{2}\right) V_{e_{2}}\right) .
$$

Simulations show that the welfare is always higher under asymmetric equilibria. It results that the gain in welfare in the sector with labor force concentration dominates the loss in the other sector. These two comparisons (unemployment rates and welfare) show that conditions edicted in proposition 2 are able to be fulfilled. 


\section{Equilibria with asymmetric sectors}

\subsection{Asymmetry in productivities}

In this section we consider that sectors differ in their productivity. Without loss of generality, let us assume that $y_{1}>y_{2}$. This asymmetry modifies the differential of entry costs $e^{*}$ which is now given by:

$$
e^{*}=\frac{\beta q}{r}\left(\frac{\left(y_{1} \Omega_{2}\left(1-u_{1}\right)-y_{2} \Omega_{1}\left(1-u_{2}\right)\right)+z(q+r)\left(u_{1}-u_{2}\right)}{\Omega_{1} \Omega_{2}}\right)
$$

with $\Omega_{i}=(r+q) u_{i}+\beta q\left(1-u_{i}\right) \quad \forall i$.

The equilibrium is given by the system of equations (18) and yields the following result:

Proposition 3 Asymmetric productivities among sectors $\left(y_{1}>y_{2}\right)$ imply that there exists at least one equilibrium with concentration of the labor force in the sector with the highest productivity $\left(N_{1}^{*}>N_{2}^{*}\right)$. At this equilibrium, the unemployment rate in sector 1 is lower than in sector 2 , and wages are higher than in sector 2.

Proof. see Appendix 4.

Not surprisingly, the labor force concentrates in the sector with the highest productivity whether the network effect is endogenous or not. When the probability of transmission is exogenous, a higher level of productivity implies a higher level of expected utility for unemployed workers through a direct effect. This effect is reinforced by an indirect effect that goes through the decrease of the unemployment rate due to a higher productivity. The decrease of the unemployment rate implies a higher utility for the unemployed workers. Then, the threshold worker who is indifferent between working in sector 1 or in sector 2 faces a positive differential of entry costs $e^{*}>0$. It results that a higher share of unemployed workers is incited to choose sector 1.

When the probability of transmission is endogenous, these effects are reinforced by the fact that a rise in the labor force in the high productivity sector increases the threshold level of the cost differential $\frac{\partial e^{*}}{\partial N_{1}}>0$.

Note that when workers do not benefit from any bargaining power $(\beta=0)$, the difference in productivity does not affect the equilibrium that remains the one with labor force equally shared between the two sectors $\left(N_{1}=\frac{1}{2}\right)$. Indeed, in this specific case, since workers do not benefit from any bargaining power, the expected utility of an unemployed worker is given and equals the discounted income received when unemployed $\left(\frac{z}{r}\right)$. 


\subsection{Asymmetry in entry costs}

In this section we assume that the fixed sectoral component of the entry costs, namely $\bar{e}_{i}$, differ across sectors. Without loss of generality, let us assume that $\bar{e}_{1}>\bar{e}_{2}$. However, the distribution function $F(\tilde{e})$ and then, the second component of the entry costs is unchanged and symmetric across sectors.

First, suppose that the probability of transmission is exogenous and identical among sectors. Then unemployment rates are given by the sectoral equilibrium (section 2.3) and the labor force size among sectors is determined by the differential of entry costs. Given that sectors are perfectly symmetric except for entry costs $\left(y_{1}=y_{2}=y\right.$ and $\left.p_{1}=p_{2}=p\right)$, the expected utility differential is given by $\Delta V=0$. The marginal individual who is indifferent between both sectors is the one with $\Delta V=e^{*}=0$. Given that the entry costs have two components, $e=\tilde{e}+\bar{e}$, the worker who is indifferent between the two sectors is the one who has the individual component of the entry costs that satisfies $\tilde{e}^{*}=-\bar{e}<0$. Therefore, the labor force participating in each sector is given by:

$$
N_{i}^{*}=\chi_{i} \int_{-\infty}^{\tilde{e}^{*}} f(e) d e+\left(1-\chi_{i}\right) \int_{\tilde{e}^{*}}^{\infty} f(e) d e
$$

where $f(e)$ is the density of the distribution function $F$ with $\chi=1$ for $i=1$ and $\chi=0$ for $i=2$. It follows that $N_{1}^{*}<\frac{1}{2}$ since $\tilde{e}^{*}<0$ and $F(0)=\frac{1}{2}$. It results that workers concentrate in sector 2 .

Now, if we consider that the probability of transmission is endogenous, the differential of entry costs for the marginal worker who is indifferent between working in sector 1 or 2 is now given by

$$
\tilde{e}^{*}=(y-z) \beta q \frac{r+q}{r}\left(\frac{u_{2}-u_{1}}{\left((r+q) u_{1}+q \beta\left(1-u_{1}\right)\right)\left((r+q) u_{2}+\beta q\left(1-u_{2}\right)\right)}\right)-\bar{e}
$$

Workers who have a differential of entry costs $\tilde{e}$ lower than $\tilde{e}^{*}$ choose to work in sector 1 , whereas the others choose the sector 2 . We can immediately deduce that for a given $N_{1}$, the corresponding $\tilde{e}^{*}$ is lower than in the symmetric case (i.e. $\left.\bar{e}=0\right)$. Then $\left(\frac{1}{2}, \frac{1}{2}\right)$ is not an equilibrium since for $N_{1}=\frac{1}{2}$ we have $\tilde{e}^{*}=-\bar{e}<0$. Finally, since $F\left(\tilde{e}^{*}(0)\right) \geq 0$, there exists at least one equilibrium with $\left(N_{1}, N_{2}\right)=(x, 1-x)$ and $x<\frac{1}{2}$.

We can immediately deduce the following result:

Proposition 4 Asymmetry in entry costs $\left(\bar{e}_{1}>\overline{e_{2}}\right)$ implies that there exists at least one equilibrium with concentration in sector 2 where entry costs $\bar{e}$ are lower. At this equilibrium, sector 2 benefits from a lower unemployment rate and higher wages. 
Similarly to the symmetric case, one can argue that it may exist multiple equilibria ${ }^{6}$. However, when only one equilibrium exists, it implies a concentration of the labor force in the sector with the highest historical network effect.

\subsection{Combining asymmetries between sectors}

The two previous sections have highlighted two opposite effects: On the one hand, the sector that benefits from a higher productivity attracts more labor force which results in a lower unemployment rate and higher wages. On the other hand, a lower fixed entry cost $\bar{e}_{i}$ also attracts labor force and implies a lower unemployment rate.

Let us combine both asymmetries, namely sector 1 benefits from a higher productivity and sector 2 from lower fixed entry costs. Considering an endogenous probability of transmission, the impact of both asymmetries on the threshold individual component of the entry costs $\tilde{e}^{*}$ is given by:

$$
d \tilde{e}^{*}=\frac{\partial e^{*}}{\partial y_{1}} d y_{1}-d \bar{e}
$$

Then a higher concentration in sector 2 means that the combination of the two effects implies a decrease in the cost differential $\tilde{e}^{*}: d \tilde{e}^{*}<0$. Using equation (26), (27) and (28) (from Appendix 4), it can be rewritten as:

$$
\frac{d y_{1}}{d \bar{e}}<\frac{\beta q\left(1-u_{1}\right)}{r \Omega_{1}}
$$

Then, we can deduce the following proposition :

\section{Proposition 5}

$$
d \bar{e}>\frac{1}{r} d y_{1}
$$

is a sufficient condition ensuring that workers concentrate in the low productivity sector.

Proof. Directly from $\Omega_{1}=u_{1}(r+q)+\beta q\left(1-u_{1}\right)$.

This constraint shows that a the differential of entry costs weighted by the discount rate must be higher than the productivity gap between sectors to ensure that workers concentrate in the low productivity sector.

\footnotetext{
${ }^{6}$ Based on Appendix 2 one can show that we face multiple equilibria with asymmetric entry costs when $f\left(\tilde{e}_{1}^{*}\right)(y-z) \beta q \frac{r+q}{r}\left(\frac{u_{2}^{\prime}}{\Omega_{2}^{2}}-\frac{u_{1}^{\prime}}{\Omega_{1}^{2}}\right) \geq 0$ where $\tilde{e}_{1}^{*}$ corresponds to the equilibrium that generates less concentration across sectors.
} 


\section{Conclusion: Explaining the Portuguese case study on the French labour market}

Our theoretical model and the results we derive explain three main specificities of the Portuguese labor force on the French labor market: an especially low unemployment rate, a high sector concentration and the intergenerational transmission of the both previous features.

Contrary to commonly believes, Portuguese immigration in France is much more recent than the Italian and Spanish ones (see Pereira (2012)). Until the end of the 50's, Portuguese migrations were mostly concentrated towards African countries. The rise in Portuguese migrations in the beginning of the 60 's can be explained by two historical factors: anti colonial wars in the traditional host countries (Angola, Guinea Bissau, Mozambique) and a wave of repression of the dictatorial regime. During this period, migrations towards France were prohibited by the Portuguese government which explains that Portuguese migrations had grounded on a clandestine migratory network. This illegal immigration was tolerated by the French government due to labour force needs in several sectors such as construction trade or car construction. Thus, from the beginning, Portuguese migration has forged more than others a community network. While productivity levels were quite similar in many segments of the industrial sector, the Portuguese community concentrated in the construction sector as raised in our Section 3 (asymmetric equilibria with symmetric sectors). Then, this initial sector concentration has favored the distribution across sectors through two channels: the network and the entry costs effects. Previous migrants working in the construction sector were more likely to hear speaking about job offers in this sector and forward the information through the community. Secondly, members of this community had accumulated a sectoral specific human capital which has reduced the relative entry costs in this sector.

These two induced effects implied that Portuguese labor force remained concentrated in this sector, as shown in our section devoted to asymmetric sectors (section 4), while the relative productivity was decreasing .

On the French labor market, Portuguese keep on concentrating in the construction sector due to social network (more Portuguese in this sector), lower entry costs (community specific human capital) while the average wage is lower. These mechanisms replicated for the second generation of migrants so that they are more likely to opt for vocational studies in order to work in construction trades compared to children of other migrants' communities 
as shown by Brinbaum and Kieffer (2009) and Lainé and Okba (2005).

\section{Appendix}

\subsection{Appendix 1: The sectoral equilibrium}

The equilibrium unemployment rate and the equilibrium value of the labor market tightness verify the system:

$$
\left\{\begin{array}{l}
\phi\left(\theta_{i}^{*}, u_{i}^{*}\right)=0 \\
\psi\left(\theta_{i}^{*}, u_{i}^{*}\right)=0
\end{array}\right.
$$

With

$$
\begin{array}{r}
\phi\left(\theta_{i}, u_{i}\right)=q\left(1-u_{i}\right)-\theta_{i} c\left(\theta_{i}\right)\left(u_{i}+p\left(1-u_{i}\right)\right) \\
\psi\left(\theta_{i}, u_{i}\right)=\frac{h}{c\left(\theta_{i}\right)\left(u_{i}+p\left(1-u_{i}\right)\right)}-\frac{(1-\beta)(y-z)}{r+q+\beta q \frac{\left(1-u_{i}\right)}{u_{i}}}
\end{array}
$$

We deduce :

$$
\begin{gathered}
\phi_{u_{i}}\left(\theta_{i}^{*}, u_{i}^{*}\right)=-q-\theta_{i}^{*} c\left(\theta_{i}^{*}\right)(1-p)<0 \\
\phi_{p_{i}}\left(\theta_{i}^{*}, u_{i}^{*}\right)=-\theta_{i}^{*} c\left(\theta_{i}^{*}\right)\left(1-u_{i}^{*}\right)<0 \\
\phi_{\theta_{i}}\left(\theta_{i}^{*}, u_{i}^{*}\right)=-\left(c\left(\theta_{i}^{*}\right)+\theta_{i}^{*} c^{\prime}\left(\theta_{i}^{*}\right)\right)\left(u_{i}^{*}+p_{i}\left(1-u_{i}^{*}\right)\right)<0
\end{gathered}
$$

and

$$
\begin{gathered}
\psi_{\theta_{i}}\left(\theta_{i}^{*}, u_{i}^{*}\right)=\frac{-h c^{\prime}\left(\theta_{i}^{*}\right)}{c\left(\theta_{i}^{*}\right)^{2}\left(u_{i}^{*}+p_{i}\left(1-u_{i}^{*}\right)\right)}>0 \\
\psi_{u_{i}}\left(\theta_{i}^{*}, u_{i}^{*}\right)=-\frac{h(1-p)}{c\left(\theta_{i}^{*}\right)\left(u_{i}^{*}+p_{i}\left(1-u_{i}^{*}\right)\right)^{2}}-\frac{(1-\beta)(y-z) \beta q}{\left(r+q+\beta q \frac{\left(1-u_{i}^{*}\right)}{u_{i}^{*}}\right)^{2} u_{i}^{* 2}}<0 \\
\psi_{p_{i}}\left(\theta_{i}^{*}, u_{i}^{*}\right)=\frac{-h\left(1-u_{i}^{*}\right)}{c\left(\theta_{i}^{*}\right)\left(u_{i}^{*}+p_{i}\left(1-u_{i}^{*}\right)\right)^{2}}<0 \\
\psi_{y}\left(\theta_{i}^{*}, u_{i}^{*}\right)=\frac{-(1-\beta)}{r+q+\beta q \frac{\left(1-u_{i}^{*}\right)}{u_{i}^{*}}}<0
\end{gathered}
$$

From the implicit function theorem, we are able to deduce:

$$
\frac{d u_{i}^{*}}{d p_{i}}=\frac{-\psi_{p_{i}}+\frac{\psi_{\theta_{i}} \phi_{p_{i}}}{\phi_{\theta_{i}}}}{-\psi_{u_{i}}+\frac{\psi_{\theta_{i}} \phi_{u_{i}}}{\phi_{\theta_{i}}}}<0
$$

and

$$
\frac{d u_{i}^{*}}{d y_{i}}=\frac{-\psi_{y_{i}}}{\psi_{u_{i}}-\frac{\psi_{\theta_{i}} \phi_{u_{i}}}{\phi_{\theta_{i}}}}<0
$$


Equations (3), (4), (5), (6), (7) and (8) imply that the total surplus of each match, the wage and the value function of an unemployed worker satisfy the following conditions :

$$
\begin{aligned}
S_{i} & =\frac{y_{i}-z}{r+q+\beta s_{i}} \\
w_{i} & =y-(r+q)(1-\beta) S_{i} \\
V_{u, i} & =\frac{y_{i}-(r+q) S_{i}}{r} \\
V_{e, i} & =\frac{w_{i}+q V_{u, i}}{r+q}
\end{aligned}
$$

From Equations (2) and (10), we deduce that $s=q \frac{1-u}{u}$. Therefore, at the equilibrium we obtain

$$
\begin{aligned}
S_{i}^{*} & =\frac{y_{i}-z}{r+q+q \beta \frac{1-u_{i}^{*}}{u_{i}^{*}}} \\
\frac{d S_{i}^{*}}{d p_{i}} & =\frac{q \beta\left(y_{i}-z\right)}{\left(r+q+q \beta \frac{1-u_{i}^{*}}{u_{i}^{*}}\right)^{2} u_{i}^{2}} \frac{d u_{i}^{*}}{d p_{i}}<0 \\
\frac{d w_{i}^{*}}{d p_{i}} & =-(r+q)(1-\beta) \frac{d S_{i}^{*}}{d p_{i}}>0 \\
w_{i}^{*} & y_{i}-(r+q)(1-\beta) S_{i}^{*} \\
\frac{V_{u, i}^{*}}{d V_{u, i}^{*}} & =\frac{y_{i}-(r+q) S_{i}^{*}}{r} \\
d p_{i} & -\frac{(r+q)}{r} \frac{d S_{i}^{*}}{d p_{i}}>0
\end{aligned}
$$

\subsection{Appendix 2: Multiple equilibria}

i) symmetric equilibrium:

We know that $e^{*}=\Delta V\left(u_{1}, u_{2}\right)$. Replacing $V$ we can rewrite $e^{*}$ as:

$$
e^{*}=(y-z) \beta q \frac{r+q}{r}\left(\frac{u_{2}-u_{1}}{\left((r+q) u_{1}+q \beta\left(1-u_{1}\right)\right)\left((r+q) u_{2}+\beta q\left(1-u_{2}\right)\right)}\right)
$$

and $N_{1}^{*}$ satisfies $N_{1}=F\left(e^{*}\left(N_{1}\right)\right)$.

The equilibrium values of $N_{1}$ are the points where $F\left(e^{*}\right)$ crosses the $45^{\circ}$ line in the $N_{1^{-}}$ $F\left(e^{*}\right)$ plane. We know that $F\left(e^{*}(1 / 2)\right)=F(0)=1 / 2$. Then $\left(N_{1}^{*}, N_{2}^{*}\right)=\left(\frac{1}{2}, \frac{1}{2}\right)$ is an equilibrium. 
ii) multiple equilibria:

Let denote $\Omega_{1}=\left((r+q) u_{1}+q \beta\left(1-u_{1}\right)\right)$ and $\Omega_{2}=\left((r+q) u_{2}+\beta q\left(1-u_{2}\right)\right)$.

$$
\begin{aligned}
\frac{\partial F\left(e^{*}\right)}{\partial N_{1}}= & f\left(e^{*}\right)(y-z) \beta q \frac{r+q}{r} \times \\
& \left(\frac{\Omega_{1} \Omega_{2}-\left(u_{2}-u_{1}\right)(r+q-\beta q) \Omega_{2}}{\left(\Omega_{1} \Omega_{2}\right)^{2}} u_{1}^{\prime}+\frac{\Omega_{1} \Omega_{2}-\left(u_{2}-u_{1}\right)(r+q-\beta q) \Omega_{1}}{\left(\Omega_{1} \Omega_{2}\right)^{2}} u_{2}^{\prime}\right) \\
= & f\left(e^{*}\right)(y-z) \beta q \frac{r+q}{r}\left(\frac{-1}{\Omega_{1}^{2}} u_{1}^{\prime}+\frac{1}{\Omega_{2}^{2}} u_{2}^{\prime}\right) \geq 0
\end{aligned}
$$

since $u_{1}^{\prime}=\frac{\partial u_{1}}{\partial N_{1}}<0$ and $u_{2}^{\prime}=\frac{\partial u_{2}}{\partial N_{1}}>0$.

Knowing that $\frac{\partial F\left(e^{*}\right)}{\partial N_{1}} \geq 0$, the existence of multiple ewuilibria requires two conditions: a) $\lim _{N_{1}^{*} \longrightarrow 0} F\left(e^{*}\left(N_{1}\right)\right) \geq 0$ and $\lim _{N_{1}^{*} \longrightarrow 1} F\left(e^{*}\left(N_{1}\right)\right) \leq 1$ and

b) The slope of $F\left(e^{*}\left(N_{1}\right)\right)$ must be larger than one at an equilibrium.

We know that when $N_{1}$ tends to zero, $p_{1}$ is small and $u_{1}$ is large. Conversely, $p_{2}$ is large and $u_{2}$ is small then $u_{1}>u_{2}$. This implies $e^{*}<0$ and therefore $0 \leq F\left(e^{*}(0)\right)<1 / 2$. When $N_{1}$ tends to 1 ( $N_{2}$ tends to 0 ), $p_{1}$ is large and $u_{1}$ is small. Conversely, $p_{2}$ is small and $u_{2}$ is large then $u_{2}>u_{1}$. This implies $e^{*}>0$ and therefore $1 \geq F\left(e^{*}(1)\right)>1 / 2$.

If $(1,0)$ and $(0,1)$ are equilibria, multiple equilibria exist.

If $(1,0)$ and $(0,1)$ are not equilibria then $1 \geq F\left(e^{*}(0)\right)>0$ and $\frac{\partial F\left(e^{*}\right)}{\partial N_{1}}>1$ at point $\left(N_{1}^{*}, N_{2}^{*}\right)=\left(\frac{1}{2}, \frac{1}{2}\right)$ is a sufficient condition to ensure multiple equilibria (see Figure1).

At the point $N_{1}=N_{2}=1 / 2$ we have $u_{1}=u_{2}=u_{s}^{*}$ and $u_{1}^{\prime}=\frac{\partial u_{1}}{\partial p_{1}} \frac{\partial p_{1}}{\partial N_{1}}=-u_{2}^{\prime}=u^{\prime}<0$ and $e^{*}=0$, so that:

$$
\left.\frac{\partial F\left(e^{*}\right)}{\partial N_{1}}\right|_{1 / 2}=-f(0)(y-z) \beta q \frac{r+q}{r} \frac{2 u^{\prime}}{\left((r+q) u_{s}^{*}+\beta q\left(1-u_{s}^{*}\right)\right)^{2}}>0
$$

A sufficient condition ensuring multiple equilibria is then:

$$
\left.\frac{\partial F\left(e^{*}\right)}{\partial N_{1}}\right|_{1 / 2}>1 \Longleftrightarrow(y-z)>\frac{r}{(r+q) \beta q} \frac{\left((r+q) u_{s}^{*}+\beta q\left(1-u_{s}^{*}\right)\right)^{2}}{-2 u^{\prime} f(0)}
$$




\subsection{Appendix 3: Comparison of equilibria outcome}

Let us consider Equilibrium $C_{1}$ with $\left(N_{1}^{*}, N_{2}^{*}\right)=(x, 1-x)$ with $x>\frac{1}{2}$ (the symmetric reasoning works for equilibrium $C_{2}$ with $\left.x<\frac{1}{2}\right)$. As we know that $\frac{d u_{i}^{*}}{d p_{i}}<0$, and $p_{i}$ increases with $N_{i}$, it results that the unemployment rate of the symmetric solution $u_{s}$ is higher than the unemployment rate of the asymmetric solution in the region where workers concentrate $u_{1}^{*}: u_{1}^{*}<u_{S}$ which implies a lower surplus at the symmetric solution $S_{1}<S_{s}$. To evaluate the welfare levels at both equilibria, we determine the impact of the unemployment rate on the social welfare evaluated by $u_{i} V_{u_{i}}+\left(1-u_{i}\right) V_{e_{i}}$. Combining Equations (21), (22), (23) and (24), we obtain:

$$
u_{i} V_{u_{i}}+\left(1-u_{i}\right) V_{e_{i}}=\frac{\beta\left(1-u_{i}\right)\left(q y+r u_{i}(y-z)\right)+(q+r) u_{i} z}{r\left((q+r) u_{i}+\beta q\left(1-u_{i}\right)\right)}
$$

Deriving with respect to $u_{i}$ gives :

$$
\begin{aligned}
\frac{\partial\left(u_{i} V_{u_{i}}+\left(1-u_{i}\right) V_{e_{i}}\right)}{\partial u_{i}} & =-\frac{\beta(y-z)\left((r+q)\left(r u_{i}^{2}+q\right)-\beta q r\left(1-u_{i}\right)^{2}\right)}{r\left((q+r) u_{i}+\beta q\left(1-u_{i}\right)\right)^{2}} \\
& =-\frac{\beta(y-z)\left((1-\beta) q r\left(1+u_{i}^{2}\right)+\left(q+r u_{i}\right)^{2}\right)}{r\left((q+r) u_{i}+\beta q\left(1-u_{i}\right)\right)^{2}}<0
\end{aligned}
$$

and therefore

$$
u_{1}^{*} V_{u_{1}}+\left(1-u_{1}^{*}\right) V_{e_{1}}>u_{s}^{*} V_{u_{1}}+\left(1-u_{s}^{*}\right) V_{e_{1}}
$$

Moreover, we can derive:

$$
\frac{\partial^{2}\left(u_{i} V_{u_{i}}+\left(1-u_{i}\right) V_{e_{i}}\right)}{\partial u_{i}^{2}}=\frac{2(1-\beta) \beta q(q+r)^{2}(y-z)}{r\left((r+q) u_{i}+\beta\left(q\left(1-u_{i}\right)\right)^{3}\right.}>0
$$

\subsection{Appendix 4: Proof of proposition 3}

Let us check if $e^{*}$ with $y_{1}>y_{2}=y$ is higher or lower than in the symmetric case. The impact of $y_{1}$ on $e^{*}$ is given by:

$$
\frac{d e^{*}}{d y_{1}}=\frac{\partial e^{*}}{\partial u_{1}} \frac{\partial u_{1}}{\partial y_{1}}+\frac{\partial e^{*}}{\partial y_{1}}
$$

with

$$
\frac{\partial e^{*}}{\partial u_{1}}=-\frac{(r+q) q\left(y_{1}-z\right) \beta}{r \Omega_{1}^{2}}<0 \quad \text { and } \quad \frac{\partial e^{*}}{\partial u_{2}}=\frac{(r+q) q\left(y_{2}-z\right) \beta}{r \Omega_{2}^{2}}>0
$$

from $(20)$,

$$
\frac{\partial u_{i}}{\partial y_{i}}=\frac{-\psi_{y_{i}}}{\psi_{u_{i}}-\frac{\psi_{\theta_{i}} \phi_{u_{i}}}{\phi_{\theta_{i}}}}<0
$$


and

$$
\frac{\partial e^{*}}{\partial y_{1}}=\frac{q\left(1-u_{1}\right) \beta}{r \Omega_{1}}>0
$$

We can conclude that $\frac{d e^{*}}{d y_{1}}>0$.

When probabilities of transmission are exogenous, since for the symmetric case $e^{*}=0$, $\frac{d e^{*}}{d y_{1}}>0$ implies that $e^{*}>0$ when $y_{1}>y_{2}=y$ and since

$$
N_{1}^{*}=\chi_{i} \int_{-\infty}^{e^{*}} f(e) d e
$$

we have $N_{1}>\frac{1}{2}$.

When probabilities of transmission are endogenous, $\frac{d e^{*}}{d y_{1}}>0$ applies for a given $N_{1}$. Then, for $N_{1}=0.5$, we have $e^{*}>0$ for $y_{1}>y_{2}=y$ and $F\left(e^{*}\left(\frac{1}{2}\right)\right)>\frac{1}{2}$ so that $\left(\frac{1}{2}, \frac{1}{2}\right)$ is not an equilibrium anymore. Moreover, we know that $F\left(e^{*}(0) \geq 0\right)$ and $F\left(e^{*}(1) \leq 1\right)$. Therefore, there exists at least one equilibrium with $\left(N_{1}^{*}, N_{2}^{*}\right)=(x, 1-x)$ and $1 \geq x>\frac{1}{2}$.

Finally, we can check that $\left(N_{1}, N_{2}\right)=(0,1)$ is not an equilibrium. If $(0,1)$ is an asymmetric equilibrium in the symmetric case, then at a given $N_{1}$, we know that $\frac{\partial e^{*}}{\partial y_{1}}>0$ that implies that $F\left(e^{*}\right)>0$. For the same reasons, if $(0,1)$ is not an equilibrium in the symmetric case, then it is neither an equilibrium in the asymmetric one with $y_{1}>y_{2}=y$. 


\section{References}

Addison, J. T. and Portugal, P. (2002). Job search methods and outcomes. Oxford Economic Papers, 54(3):505-533.

Bartel, A. P. (1989). Where do the new us immigrants live? Journal of Labor Economics, $7(4): 371-391$.

Bauer, T., Pereira, P. T., Vogler, M., and Zimmermann, K. F. (2002). Portuguese migrants in the german labor market: Selection and performance. International Migration Review, 36(2):467-491.

Blau, D. M. and Robins, P. K. (1990). Job search outcomes for the employed and unemployed. Journal of political Economy, 98(3):637-655.

Boorman, S. A. (1975). A combinatiorial optimization model for transmission of job information through contact networks. The bell journal of economics, pages 216-249.

Brinbaum, Y. and Kieffer, A. (2009). Les scolarités des enfants d'immigrés de la sixième au baccalauréat: différenciation et polarisation des parcours. Population, 64(3):561-610.

Calvó-Armengol, A. (2004). Job contact networks. Journal of economic Theory, 115(1):191-206.

Calvó-Armengol, A. and Jackson, M. O. (2002). Social networks in determining employment and wages: Patterns, dynamics, and inequality.

Calvó-Armengol, A. and Zenou, Y. (2005). Job matching, social network and word-ofmouth communication. Journal of urban economics, 57(3):500-522.

Carrington, W. J., Detragiache, E., and Vishwanath, T. (1996). Migration with endogenous moving costs. The American Economic Review, pages 909-930.

Chiswick, B. R., Lee, Y. L., and Miller, P. W. (2002). The determinants of the geographic concentration among immigrants: Application to australia.

Chiswick, B. R. and Miller, P. W. (1995). The endogeneity between language and earnings: International analyses. Journal of labor economics, 13(2):246-288.

Domingues Dos Santos, M. (2005). Travailleurs maghrébins et portugais en france. le poids de l'origine. Revue économique, 56(2):447-464. 
Domingues dos Santos, M. and Wolff, F.-C. (2010). Pourquoi les immigrés portugais veulent-ils tant retourner au pays? Economie prevision, (4):1-14.

Dustmann, C. (2000). Temporary migration and economic assimilation. Technical report, IZA Discussion Papers.

Granovetter, M. (1974). Getting a job: A study of contacts and careers, cambridge. $M A$ : Harvard.

Holzer, H. J. (1988). Search method use by unemployed youth. Journal of labor economics, $6(1): 1-20$.

Jackson, M. O. and Wolinsky, A. (1996). A strategic model of social and economic networks. Journal of economic theory, 71(1):44-74.

Lainé, F. and Okba, M. (2005). Jeunes de parents immigrés: de l'école au métier.

Pereira, V. (2012). La dictature de Salazar face à l'émigration: l'État portugais et ses migrants en France (1957-1974). Presses de Sciences Po.

Pissarides, C. A. (2000). Equilibrium unemployment theory. MIT press. 